\title{
Detection of Leishmania infantum DNA mainly in Rhipicephalus sanguineus male ticks removed from dogs living in endemic areas of canine leishmaniosis
}

Laia Solano-Gallego ${ }^{1,3,5^{*}}$, Luca Rossi ${ }^{2}$, Anna Maria Scroccaro ${ }^{3}$, Fabrizio Montarsi ${ }^{4}$, Marco Caldin ${ }^{3}$, Tommaso Furlanello ${ }^{3}$ and Michele Trotta $^{3}$

\begin{abstract}
Background: Sand flies are the only biologically adapted vectors of Leishmania parasites, however, a possible role in the transmission of Leishmania has been proposed for other hematophagous ectoparasites such as ticks. In order to evaluate natural infection by Leishmania infantum in Rhipicephalus sanguineus ticks, taking into account its close association with dogs, 128 adult $R$. sanguineus ticks removed from 41 dogs living in endemic areas of canine leishmaniosis were studied.

Methods: Individual DNA extraction was performed from each tick and whole blood taken from dogs. Dog sera were tested for $\lg G$ antibodies to $L$. infantum antigen by ELISA and L. infantum real-time PCR was performed from canine whole blood samples and ticks.

Results: Leishmania infantum PCR was positive in 13 ticks (10.1\%) including one female, (2.0\%) and 12 males (15.2\%), and in only five dogs (12.2\%). Male ticks had a significantly higher infection rate when compared to female R. sanguineus. The percentage of L. infantum seroreactive dogs was 19.5\%. All but two PCR positive dogs were seroreactive. Leishmania infantum PCR positive ticks were removed from seropositive and seronegative dogs with a variety of PCR results.

Conclusions: This study demonstrates high prevalence of L. infantum DNA in $R$. sanguineus ticks removed from $L$. infantum seropositive and seronegative dogs. The presence of $L$. infantum DNA was detected mainly in male ticks possibly due to their ability to move between canine hosts and feed on several canine hosts during the adult life stage. Additional studies are needed to further explore the role of $R$. sanguineus ticks and in particular, male adults, in both the epidemiology and immunology of L. infantum infection in dogs in endemic areas.
\end{abstract}

Keywords: Leishmania infantum, Rhipicephalus sanguineus ticks, PCR, Dog

\section{Background}

Canine leishmaniosis due to Leishmania infantum is a major zoonotic disease endemic in more than 70 countries in the world. It is present in regions of southern Europe, Africa, Asia, South and Central America [1]. It has been estimated, based on seroprevalence studies

\footnotetext{
* Correspondence: Isolano@rvc.ac.uk; laia.solano@uab.cat 'Department Pathology and Infectious Diseases, Royal Veterinary College of London, United Kingdom

${ }^{3}$ Laboratorio e Clinica Veterinari San Marco, Padua, Italy

Full list of author information is available at the end of the article
}

from Italy, Spain, France and Portugal that 2.5 million dogs in these countries are infected [2]. Furthermore, L. infantum infection is spreading north in Europe [3] and has reached the foothills of the Alps in Northern Italy [4]. Dogs are the main reservoir for this infection and the disease can be fatal sometimes if not treated in people and dogs.

Leishmania infantum is a diphasic parasite that completes its life cycle in two hosts, a sand fly, which harbors the flagellated extracellular promastigotes and a mammal where the intracellular amastigote parasite forms develop. Female sand flies of some species of the genus

\section{() Biomed Central}

(c) 2012 Solano-Gallego et al.; licensee BioMed Central Ltd. This is an Open Access article distributed under the terms of the Creative Commons Attribution License (http://creativecommons.org/licenses/by/2.0), which permits unrestricted use, distribution, and reproduction in any medium, provided the original work is properly cited. 
Phlebotomus (Old World) are the proven vectors of $L$. infantum transmission in humans and dogs [5]. However, other less common transmission routes have been proven in dogs. The transmission of L. infantum through blood products has been reported in dogs that received blood transfusions from infected donors in North America [6,7]. Transmission of infection by infected canine blood products has been documented and is of special concern in areas where blood donors may be carriers of infection $[8,9]$. Vertical in-utero transmission from dam to its offspring has been documented $[10,11]$ and venereal transmission has been also reported in dogs [12]. Direct dog-to dog transmission without involvement of a hematophageous vector has been suspected in some cases of infection in areas where vectors of the disease are apparently absent [13]. In addition, ticks and fleas have been proposed as alternative vectors of $L$. infantum transmission $[14,15]$.

Rhipicephalus sanguineus, known as the brown dog tick, is an ectoparasite of domestic dogs found almost worldwide, mainly in tropical and temperate climates [16]. Rhipicephalus sanguineus is a three-host tick that feeds primarily on dogs and occasionally on a diverse range of wild and domestic animals, including humans $[17,18]$.

Rhipicephalus sanguineus ticks are known vectors and reservoirs of canine pathogens such as Babesia vogeli and Rickettsia conorii. Little is known of the relationship between $R$. sanguineus ticks and certain pathogens that they might transmit. The complete life cycle of Hepatozoon canis in R. sanguineus tick has recently been described [19]. Studies of this nature are lacking for other pathogens. For instance, the mechanisms involved in the interaction between $R$. sanguineus and L. infantum are largely unknown. Although, it is suspected that $R$. sanguineus ticks might be involved in the transmission of L. infantum [15], the role of the brown dog tick in the epidemiology of L. infantum infection remains uncertain and is an issue of great importance for dogs and humans [20].

In order to evaluate natural infection by L. infantum in $R$. sanguineus ticks, taking into account its close association with dogs, $R$. sanguineus ticks removed from dogs living in endemic areas of canine leishmaniosis were studied. In this context, the aims of the present study were to detect $L$. infantum DNA in ticks collected from dogs living in endemic areas of leishmaniosis and to evaluate the relationship between Leishmania infection in ticks and dogs and the pattern of Leishmania DNA detection in ticks.

\section{Methods}

\section{Dogs and ticks}

Fifty-eight ticks removed from 26 apparently healthy dogs and two sick dogs living in an outdoor shelter in an endemic area of canine leishmaniosis (Grosseto, Central
Italy) were studied between March to May 2006 (Group 1). In addition, a total of 70 ticks were removed from 13 dogs with clinical signs and laboratory findings compatible with tick-borne diseases from April to November 2007 from veterinary clinics throughout Italy [21] (Group 2). After collection, the ticks were placed in a tube with $75 \%$ ethanol, and sent to laboratory San Marco where they were immediately stored at $-20^{\circ} \mathrm{C}$. Later, the ticks were dried at room temperature and morphologically identified [22]. The mean number of ticks collected per dog and standard deviations were $3.1 \pm 3.3$ and the range of ticks per dog was from 1 to $15 . K_{3}$ EDTA blood and sera were collected from all dogs studied from both groups and stored until use at $-20^{\circ} \mathrm{C}$. Different breeds and mixed-breed of dogs were studied in both groups.

The mean age \pm SD of dogs in Group 1 was $5.05 \pm 2.13$ years. The information on age was available only for 17 dogs. Sixteen were females and 12 were males. All but one female dog were neutered. The mean age \pm SD of dogs in Group 2 was $5.7 \pm 4.7$ years. The information about age was available only for 9 dogs. Six were females and three were males. Gender was not available for all dogs.

\section{DNA extraction}

The ticks stored in 75\% ethanol were dried, washed with PBS and left overnight in PBS at $4^{\circ} \mathrm{C}$ to eliminate ethanol. The DNA was isolated from individual ticks by using the High Pure PCR template preparation kit (Roche, Mannheim, Germany) according to the manufacturer's instructions with some modifications. The ticks were mechanically crushed with a sterile micropestle, suspended in $200 \mu \mathrm{L}$ of tissue lysis buffer and $40 \mu \mathrm{L}$ of proteinase $\mathrm{K}(100 \mu \mathrm{g} / \mathrm{mL})$ and incubated overnight at $65^{\circ} \mathrm{C}$. The final elution volume was $100 \mu \mathrm{L}$ for each sample.

DNA extraction from canine whole blood was performed by using the High Pure PCR template preparation kit (Roche, Mannheim, Germany). $200 \mu \mathrm{L}$ of whole blood was mixed with $200 \mu \mathrm{L}$ of binding buffer with proteinase $\mathrm{K}(100 \mu \mathrm{g} / \mathrm{mL})$ and incubated for $1 \mathrm{~h}$ at $72^{\circ} \mathrm{C}$. The DNA extraction was then carried out according to the manufacturer's instructions. The final elution volume was $50 \mu \mathrm{L}$ for each sample.

Cultured L. infantum (MHOM/FR/78/LEM75) zymodeme MON-1, Leishmania tropica (MCAN/MA/90/ LEM2007) zymodeme MON-102 and Leishmania braziliensis (MCAN/BR/81/RICO) zymodeme MON-43 reference strains were studied. In vitro-cultivated L. infantum promastigotes in the logarithmic phase of growth were washed three times by centrifugation for $5 \mathrm{~min}$ at $1500 \mathrm{~g}$ in sterile PBS and counted in a hemocytometer by using a light microscope. Genomic DNA was extracted from $200 \mu \mathrm{L}$ of $73 \times 10^{6}$ promastigotes/mL as previously described [23]. 
Conventional PCR for tick mitochondrial 16 S rRNA gene The efficiency of tick DNA extraction was evaluated by amplification of the tick mitochondrial $16 \mathrm{~S}$ rRNA gene (ribosomal DNA [rDNA]) using tick-specific primers in a conventional PCR: TQ16S-1 F 5'CTGCTCAATGATTTTTTAAATTGCTGTGG 3' and TQ16S-2R 5' ACGCTGTTATCCCTAGAG 3', as previously described [24].

Each reaction was carried out in $50 \mu \mathrm{L}$ volume containing $0.5 \mu \mathrm{mol} / \mu \mathrm{L}$ of each oligonucleotide primer, $2.5 \mathrm{mM}$ of each dNTP (5PRIME GmbH, Hamburg, Germany), $5 \mu \mathrm{L}$ of $10 \times$ PCR buffer, $1 \mathrm{U}$ of Taq DNA polymerase (5PRIME GmbH, Hamburg, Germany) and $5 \mu \mathrm{L}$ of the DNA.

PCR was performed in a thermocycler (Applied Biosystem, Europe) with 1 cycle of denaturation (8 $\mathrm{min}, 94^{\circ}$ C), followed by 10 cycles of denaturation $\left(1 \mathrm{~min}, 92^{\circ} \mathrm{C}\right)$ annealing $\left(1 \mathrm{~min}, 48^{\circ} \mathrm{C}\right)$ and extension $\left(1 \mathrm{~min} 30 \mathrm{~s}, 72^{\circ} \mathrm{C}\right)$ then 32 cycles of denaturation $\left(1 \mathrm{~min} 92^{\circ} \mathrm{C}\right)$, annealing $\left(1 \mathrm{~min}, 54^{\circ} \mathrm{C}\right)$, extension $\left(1 \mathrm{~min} 30 \mathrm{~s}, 72^{\circ} \mathrm{C}\right)$ and a final extension step $\left(10 \mathrm{~min}, 72^{\circ} \mathrm{C}\right)$ as previously described [24]. DNA electrophoresis was carried out in 2.2\% FlashGel System (Lonza, Rockland, ME USA), and DNA fragments were visualized.

\section{Leishmania infantum real-time PCR and sequencing}

Real-time PCR for L. infantum DNA detection was performed in all the tick and canine samples.

We used primer and probe sequences specific for the L. infantum kinetoplast mini-circle (TIBMOLBiol, Genova, Italy) as described [23]. Real-time PCR was performed by using LightCycler FastStart DNA Master ${ }^{\text {PLUS }}$ Hybridization Probes (Roche, Mannheim, Germany) using LightCycler version 3.5.17 instrument (Roche, Mannheim, Germany). Positive and negative controls were used in all runs [23]. Leishmania tropica and L. braziliensis DNA were not detected by qPCR hybridization probes while L. infantum DNA was detected.

One positive tick sample was sequenced. The kDNA real-time PCR product was sequenced at TIB MOL Biol (Genova, Italy). Sequences were compared with sequences deposited in GenBank using BLAST hosted by the National Center for Biotechnology Information, National Institutes of Health, USA (http://www.ncbi.nlm.nih.gov).

\section{ELISA}

Canine serum anti-leishmanial antibodies were determined by ELISA, using sonicated crude L. infantum antigen as previously described [25]. Briefly, dog sera were diluted to 1:400 and incubated in L. infantum antigen-coated plates $(20 \mu \mathrm{g} / \mathrm{mL})$ for 1 hour at $37^{\circ} \mathrm{C}$. The plates were then washed with $0.05 \%$ Tween 20 in phosphate-buffered saline (PBS) and incubated with Protein A conjugated to horseradish peroxidase (1:10,000 dilution; Sigma) for 1 hour at $37^{\circ} \mathrm{C}$. Plates were washed again with $0.05 \%$ PBS-Tween 20 . The plates were developed by adding the substrate solution ortho-phenylenediamine (SIGMA FAST OPD, Sigma). The reaction was stopped with $50 \mu \mathrm{l}$ of $3 \mathrm{MH}_{2} \mathrm{SO}_{4}$. Absorbance values were read at $492 \mathrm{~nm}$ in an automatic microELISA reader (PROGRAMMABLE MPT READER DV 990BV4, N.T. Laboratory, Italy). All determinations included the serum from a sick dog with a confirmed infection as positive control (calibrator) and serum from a healthy dog as a negative control. The result was quantified as units (U) related to a positive canine serum used as a calibrator and arbitrarily set at $100 \mathrm{U}$. The cutoff was established at $14 \mathrm{U}$ (mean $+4 \mathrm{SD}$ of values from 32 dogs from non-endemic areas) and the results above this value were considered positive.

\section{Statistical analysis}

Differences among groups were analyzed by means of Chi-square with Yates correction if needed and Fisher's exact test. A $p<0.05$ was considered significant.

\section{Results}

All ticks from both groups were morphologically identified as adult $R$. sanguineus ticks. A 320 bp fragment of the tick mitochondrial $16 \mathrm{~S}$ rRNA gene was amplified in all DNA tick samples from both groups. Serological and molecular results from the dogs are shown in Table 1. The molecular results from ticks are shown in Table 2. The closest matches to the amplified k-DNA product were always $L$. infantum with an identity of $95 \%$ over the 56 bp amplified sequence.

\section{Group 1}

Leishmania infantum PCR was positive in eleven ticks (18.9\%), including one female $(5.8 \%)$ and 10 males (24.4\%), and in only four dogs (14.2\%). No statistical difference was found between the percentages of positive female and male ticks (Fisher's exact test; $\mathrm{P}=0.1482$ ). The percentage of $L$. infantum seroreactive dogs was $21 \%(6 / 28)$. All but one PCR positive dog was seroreactive. Leishmania infantum PCR positive ticks were removed from both seropositive and PCR-positive dogs $(n=2)$, from both seronegative and PCR-negative dogs $(\mathrm{n}=3)$, from one seropositive and PCR negative dog and from one seronegative and PCR positive dog. The only

Table 1 Leishmania infantum seroprevalence and PCR results in dogs from groups 1 and 2

\begin{tabular}{lcc}
\hline & Serology & L. infantum PCR \\
\hline Group 1 & $6 / 28(21.4 \%)$ & $4 / 28(14.2 \%)$ \\
Group 2 & $2 / 13(15.3 \%)$ & $1 / 13(7.7 \%)$ \\
Total & $8 / 41(19.5 \%)$ & $5 / 41(12.2 \%)$ \\
\hline
\end{tabular}


Table 2 Results of $L$. infantum PCR in male and female ticks removed from dogs belonging to group 1 and 2

\begin{tabular}{llcc}
\hline \multicolumn{3}{c}{ L. infantum PCR in ticks } & \\
\hline & Females & Males & Total \\
\hline Group 1 & $1 / 17(5.8 \%)$ & $10 / 41(24.3 \%)$ & $11 / 58(18.9 \%)$ \\
Group 2 & $0 / 32(0 \%)$ & $2 / 38(5.2 \%)$ & $2 / 70(2.8 \%)$ \\
Total & $1 / 49(2.0 \%)$ & $12 / 79(15.2 \%)^{*}$ & $13 / 128(10.1 \%)$ \\
\hline
\end{tabular}

*Fisher's exact test; $\mathrm{P}=0.0166$.

PCR positive female tick was removed from a sick seropositive and PCR positive dog.

\section{Group 2}

Leishmania infantum PCR was positive in only two male ticks $(5.2 \%)$ and in only one dog (7.7\%). No statistical difference was found between the percentages of positive female and male ticks (Fisher's exact test; $\mathrm{P}=0.4965$ ). The percentage of $L$. infantum seroreactive dogs was 15.3\%. Leishmania infantum PCR positive ticks were removed from two seronegative and PCR-negative dogs.

\section{Both groups}

When results from the two dog groups were combined, L. infantum PCR was positive in 13 ticks $(10.1 \%)$ including one female (2.0\%) and 12 males (15.2\%) and in only five dogs (12.2\%). Statistical difference was found between the percentages of total Leishmania PCR positive female and male ticks when all ticks studied from both groups were taken into account (Fisher's exact test; $\mathrm{P}=0.0166$; chi-square with Yates correction $=4.380$; $\mathrm{P}=0.0364$ ). The percentage of $L$. infantum seroreactive dogs was $19.5 \%$. All but two PCR positive dogs were seroreactive. Leishmania infantum PCR positive ticks were removed from both seropositive and PCR-positive dogs $(n=2)$, from both seronegative and PCR-negative dogs $(n=5)$, from one seropositive and PCR negative dog and from one seronegative and PCR positive dog. L. infantum PCR-positive and negative ticks were removed from the same $\operatorname{dog}(\mathrm{n}=7)$.

\section{Discussion}

Ticks and fleas have been proposed as alternative vectors of L. infantum transmission whether biologically [26] or mechanically $[14,15]$. Therefore, it is important to evaluate the prevalence of $L$. infantum infection in ticks to determine whether they could represent a source of infection for dogs living in endemic areas [20]. In the present study, L. infantum DNA was detected in $R$. sanguineus ticks. The percentage of ticks positive for L. infantum DNA using PCR was lower but similar to that found in a study performed in Brazil [27]. Conversely, the $L$. infantum DNA detection rate was much higher (50\%) in ticks from Brazil [28]. It is important to highlight that previous studies evaluated ticks removed from seropositive infected dogs that are likely to have a higher parasite load and, therefore, overestimating the prevalence of Leishmania DNA detection in ticks $[27,28]$ due to the fact that canine Leishmania infection increases the probability of finding a positive tick [20]. Instead, seronegative and seropositive dogs from a dog population living in an endemic area of leishmaniosis with seroprevalence similar to that described in previous literature from southern European countries [29,30] were studied in this manuscript. Interestingly, a study performed in Sardinia failed to detect Leishmania DNA by conventional PCR in $R$. sanguineus ticks removed from dogs [31]. However, clinical and parasitological information about the dog population studied was lacking [31]. Curiously, the percentages of Leishmania infection in ticks appear to be much higher than the percentages observed in sandflies with natural infection, which are usually lower than $1 \%$ [32]. Future studies should be carried out in endemic areas to assess the prevalence of Leishmania infection in large numbers of $R$. sanguineus ticks collected from dogs.

Interestingly, this study demonstrates the presence of $L$. infantum DNA mainly in male $R$. sanguineus ticks when removed from a dog population in endemic areas. In addition, the majority of positive male ticks were removed from seronegative and PCR negative dogs. It has been shown that $R$. sanguineus male ticks readily migrate between infested, co-housed dogs in close contact due to the fact that they intermittently feed prior to and between mating on a host [33]. Therefore, they may serve as a source of Leishmania infection when they move directly between dogs or survive in the environment long enough to eventually find another canine host [33]. In addition, movement of adult ticks between dogs represents a naturally occurring form of interrupted feeding, a strategy which has been shown to shorten the feeding time necessary to allow transmission of pathogens [33]. These findings might suggest the possibility of crosstransfusion of infected blood between dogs by male $R$. sanguineus ticks when feeding. However, evidence of transmission of Leishmania infection by tick bites was reported experimentally only in two dogs $[20,26]$. Further studies need to elucidate the potential of Leishmania transmission to dogs via male tick bites.

There is little information about the development of Leishmania parasites in the tick. So far, transtadial and transovarial transmission of L. infantum DNA in $R$. sanguineus ticks have been demonstrated [34] and Leishmania DNA has been detected in salivary glands from ticks [34,35]. It remains unknown if promastigote forms can develop in the tick or if only amastigote forms migrate and invade several tissues of ticks including tick gut, ovaries or salivary gland. We propose that 
Leishmania amastigote forms could be transmitted to dogs by male $R$. sanguineus ticks that have fed on infected canine blood. However, further studies need to be performed to understand the contribution of different stages of $R$. sanguineus in the transmission of Leishmania to dogs $[34,35]$. Indeed, there is no definitive evidence that, at least, ticks in their different life stages can harbour viable $L$. infantum, because no live parasites have been cultivated from ticks in vitro or in vivo models. Another main problem to support the role of ticks in L. infantum transmission is the evidence that, till now, there are no scientific demonstrations of Leishmania biological forms (amastigote or promastigote forms) in the ticks, as assessed by dissection and morphological studies [20,28].

\section{Conclusions}

This study demonstrated a high prevalence of L. infantum DNA in $R$. sanguineus ticks removed from dogs seropositive or seronegative for $L$. infantum, and in dogs positive or negative for the presence of $L$. infantum DNA. Leishmania infantum DNA was found mainly in male ticks. Additional studies are needed to further explore the role of $R$. sanguineus ticks and in particular, male adults, in both the epidemiology and immunology of L. infantum infection in dogs in endemic areas.

\section{Competing interests}

The authors declare that they have no competing interests.

\section{Acknowledgements}

The authors would like to acknowledge Merial Italia S.L. and Laboratorio Privato Veterinario San Marco for supporting this study. The authors are also grateful to Massimo Ulivi from TIB MolBiol for his molecular technical assistance. Publication of this manuscript has been sponsored by Bayer Animal Health $\mathrm{GmbH}$.

\section{Author details}

${ }^{1}$ Department Pathology and Infectious Diseases, Royal Veterinary College of London, United Kingdom. ${ }^{2}$ Clinica Veterinaria Corridori-Rossi-Marioni, Grosseto, Italy. ${ }^{3}$ Laboratorio e Clinica Veterinari San Marco, Padua, Italy. ${ }^{4}$ Dipartimento di Ecopatologia, Istituto Zooprofilattico Sperimentale delle Venezie, Padua, Italy. ${ }^{5}$ Departament de Medicina i Cirugia Animals, Facultat de Veterinària, Universitat Autònoma de Barcelona, Cerdanyola, Barcelona 08193, Spain.

\section{Authors' contributions \\ LSG designed the study, contributed with data analysis and interpretation and wrote the manuscript. LR collected ticks and canine blood samples. AS performed DNA extraction. FM morphologically identified the ticks. MC and TF contributed with the revision of the manuscript. MT performed DNA extraction, ran the conventional and real-time PCRs, contributed with data analysis and interpretation and revision of the manuscript. All authors read and approved the final manuscript.}

Received: 04 January 2012 Accepted: 21 May 2012

Published: 21 May 2012

\section{References}

1. Baneth G, Koutinas AF, Solano-Gallego L, Bourdeau P, Ferrer L: Canine leishmaniosis - new concepts and insights on an expanding zoonosis: part one. Trends Parasitol 2008, 24(7):324-330.

2. Moreno J, Alvar J: Canine leishmaniasis: epidemiological risk and the experimental model. Trends Parasitol 2002, 18(9):399-405.
3. Miro G, Checa R, Montoya A, Hernandez L, Dado D, Galvez R: Current situation of Leishmania infantum infection in shelter dogs in northern Spain. Parasit Vectors 2012, 5(1):60.

4. Maroli M, Rossi L, Baldelli R, Capelli G, Ferroglio E, Genchi C, Gramiccia M, Mortarino M, Pietrobelli M, Gradoni L: The northward spread of leishmaniasis in Italy: evidence from retrospective and ongoing studies on the canine reservoir and phlebotomine vectors. Trop Med Int Health 2008, 13(2):256-264.

5. Killick-Kendrick R: The biology and control of phlebotomine sand flies. Clin Dermatol 1999, 17(3):279-289.

6. Giger U, Oakley DA, Owens SD, Schantz P: Leishmania donovani transmission by packed RBC transfusion to anemic dogs in the United States. Transfusion 2002, 42(3):381-383.

7. Owens SD, Oakley DA, Marryott K, Hatchett W, Walton R, Nolan TJ, Newton A, Steurer F, Schantz P, Giger U: Transmission of visceral leishmaniasis through blood transfusions from infected English foxhounds to anemic dogs. J Am Vet Med Assoc 2001, 219(8):1076-1083.

8. de Freitas E, Melo MN, da Costa-Val AP, Michalick MS: Transmission of Leishmania infantum via blood transfusion in dogs: potential for infection and importance of clinical factors. Vet Parasitol 2006, 137(1-2):159-167.

9. Tabar MD, Roura X, Francino O, Altet L, Ruiz de Gopegui R: Detection of Leishmania infantum by real-time PCR in a canine blood bank. J Small Anim Pract 2008, 49(7):325-328.

10. Rosypal AC, Troy GC, Zajac AM, Frank G, Lindsay DS: Transplacental transmission of a North American isolate of Leishmania infantum in an experimentally infected beagle. J Parasitol 2005, 91(4):970-972.

11. Boggiatto PM, Gibson-Corley KN, Metz K, Gallup JM, Hostetter JM, Mullin K, Petersen CA: Transplacental Transmission of Leishmania infantum as a Means for Continued Disease Incidence in North America. PLoS Negl Trop Dis 2011, 5(4):e1019.

12. Silva FL, Oliveira RG, Silva TM, Xavier MN: Nascimento EF. Santos RL: Venereal transmission of canine visceral leishmaniasis. Vet Parasitol; 2008.

13. Duprey ZH, Steurer FJ, Rooney JA, Kirchhoff LV, Jackson JE, Rowton ED, Schantz PM: Canine visceral leishmaniasis, United States and Canada, 2000-2003. Emerg Infect Dis 2006, 12(3):440-446.

14. Coutinho MT, Linardi PM: Can fleas from dogs infected with canine visceral leishmaniasis transfer the infection to other mammals? Vet Parasitol 2007, 147(3-4):320-325.

15. Coutinho MT, Bueno LL, Sterzik A, Fujiwara RT, Botelho JR, De Maria M, Genaro O, Linardi PM: Participation of Rhipicephalus sanguineus (Acari: Ixodidae) in the epidemiology of canine visceral leishmaniasis. Vet Parasitol 2005, 128(1-2):149-155.

16. Dantas-Torres F: The brown dog tick, Rhipicephalus sanguineus (Latreille, 1806) (Acari: Ixodidae): From taxonomy to control. Vet Parasitol 2008, 152(3-4):173-85.

17. Dantas-Torres F: Do any insects other than phlebotomine sandflies (Diptera: Psychodidae) transmit Leishmania infantum (Kinetoplastida: Trypanosomatidae) from dog to dog? Vet Parasitol 2006, 136(3-4):379-380.

18. Estrada-Pena A, Jongejan F: Ticks feeding on humans: a review of records on human-biting Ixodoidea with special reference to pathogen transmission. Exp Appl Acarol 1999, 23(9):685-715.

19. Baneth G, Samish M, Shkap V: Life cycle of Hepatozoon canis (Apicomplexa: Adeleorina: Hepatozoidae) in the tick Rhipicephalus sanguineus and domestic dog (Canis familiaris). J Parasitol 2007, 93(2):283-299.

20. Dantas-Torres F: Ticks as vectors of Leishmania parasites. Trends Parasitol 2011, 27:155-9.

21. Trotta M, Fogliazza A, Furlanello T, Solano-Gallego L: A molecular and serological study of exposure to tick-borne pathogens in sick dogs from Italy. Clin Microbiol Infect 2009, 15(Suppl 2):62-63.

22. Iori A, Di Giulio A, De Felici S: Zecche d'Italia. In Mappe parassitologiche. vol. 6. Edited by Cringoli G. Napoli: ROlando; 2005:3-199.

23. Solano-Gallego L, Rodriguez-Cortes A, Trotta M, Zampieron C, Razia L, Furlanello T, Caldin M, Roura X, Alberola J: Detection of Leishmania infantum DNA by fret-based real-time PCR in urine from dogs with natural clinical leishmaniosis. Vet Parasitol 2007, 147(3-4):315-319.

24. Halos L, Jamal T, Vial L, Maillard R, Suau A, Le Menach A, Boulouis HJ, Vayssier-Taussat M: Determination of an efficient and reliable method for DNA extraction from ticks. Vet Res 2004, 35(6):709-713.

25. Riera C, Valladares JE, Gallego M, Aisa MJ, Castillejo S, Fisa R, Ribas N, Carrio J, Alberola J, Arboix M: Serological and parasitological follow-up in dogs 
experimentally infected with Leishmania infantum and treated with meglumine antimoniate. Vet Parasitol 1999, 84(1-2):33-47.

26. McKenzie KK: A study of the transmission of canine leishmaniasis by the tick, Rhipicephalus sanguineus, and an ultrastructural comparison of the promastigote. Stillwater: Oklahoma State University; 1984.

27. Dantas-Torres F, Lorusso V, Testini G, de Paiva-Cavalcanti M, Figueredo LA Stanneck D, Mencke N, Brandao-Filho SP, Alves LC, Otranto D: Detection of Leishmania infantum in Rhipicephalus sanguineus ticks from Brazil and Italy. Parasitol Res 2010, 106(4):857-860.

28. Colombo FA, Odorizzi RM, Laurenti MD, Galati EA, Canavez F, PereiraChioccola VL: Detection of Leishmania (Leishmania) infantum RNA in fleas and ticks collected from naturally infected dogs. Parasitol Res 2011, 109(2):267-274.

29. Solano-Gallego L, Morell P, Arboix M, Alberola J, Ferrer L: Prevalence of Leishmania infantum infection in dogs living in an area of canine leishmaniasis endemicity using PCR on several tissues and serology. J Clin Microbiol 2001, 39(2):560-563.

30. Franco AO, Davies CR, Mylne A, Dedet JP, Gallego M, Ballart C, Gramiccia M, Gradoni L, Molina R, Galvez R, et al: Predicting the distribution of canine leishmaniasis in western Europe based on environmental variables. Parasitology 2011, :1-14.

31. Satta G, Chisu V, Cabras P, Fois F, Masala G: Pathogens and symbionts in ticks: a survey on tick species distribution and presence of ticktransmitted micro-organisms in Sardinia, Italy. J Med Microbiol 2011, 60(Pt 1):63-68.

32. Martin-Sanchez J, Gallego M, Baron S, Castillejo S, Morillas-Marquez F: Pool screen $P C R$ for estimating the prevalence of Leishmania infantum infection in sandflies (Diptera: Nematocera, Phlebotomidae). Trans $R$ Soc Trop Med Hyg 2006, 100(6):527-532.

33. Little SE, Hostetler J, Kocan KM: Movement of Rhipicephalus sanguineus adults between co-housed dogs during active feeding. Vet Parasitol 2007, 150(1-2):139-145.

34. Dantas-Torres F, Latrofa MS, Otranto D: Quantification of Leishmania infantum DNA in females, eggs and larvae of Rhipicephalus sanguineus. Parasit Vectors 2011, 4:56

35. Dantas-Torres F, Martins TF, de Paiva-Cavalcanti M, Figueredo LA, Lima BS, Brandao-Filho SP: Transovarial passage of Leishmania infantum kDNA in artificially infected Rhipicephalus sanguineus. Exp Parasitol 2010 125(2):184-185.

doi:10.1186/1756-3305-5-98

Cite this article as: Solano-Gallego et al: Detection of Leishmania infantum DNA mainly in Rhipicephalus sanguineus male ticks removed from dogs living in endemic areas of canine leishmaniosis. Parasites \& Vectors 2012 5:98.

\section{Submit your next manuscript to BioMed Central and take full advantage of:}

- Convenient online submission

- Thorough peer review

- No space constraints or color figure charges

- Immediate publication on acceptance

- Inclusion in PubMed, CAS, Scopus and Google Scholar

- Research which is freely available for redistribution 